\title{
Design Analysis and Comparison between Standard and Rotary Porting Systems for IC Engine
}

\author{
Remy Palmisano and Hoi Dick $\mathrm{Ng}^{\dagger}$ \\ Department of Mechanical and Industrial Engineering, Concordia University, Montréal, QC, H3G 1M8, Canada
}

(Received date: January 26, 2011 ; revised date: May 10, 2011 ; Accepted date: June 15, 2011)

\begin{abstract}
Many porting systems for internal combustion engines have been tried and tested over the years, however the basic spring actuated poppet valve system has prevailed over the last century. In the goal to lower engine output parasitic losses, a simple rotary valve porting system design is proposed and analyzed. The proposed design concept takes into consideration and combines all the prominent advantages of many ealier mutlitiple design variations over the past century. The inherent primary advantage of such a rotary porting system is the elimination of reciprocating components, thus lowering vibration, and removal of highly stiff springs which contribute to considerable system power loss. Comparable sized 3-D representations of both systems are constructed in CAD (Computer Aided Design) software in order to run mechanical and fluid simulations to validate the efficiency advantage of a rotary valve porting system. Using Pro/Engineer Mechanism Dynamics module, the minimum torque required to actuate both systems at $2000 \mathrm{rpm}$ and $3000 \mathrm{rpm}$ is determined. Fluid simulations are performed using a commercial software CFDesign V10. Volumetric flow rates are compared during the intake stroke as well as turbulence intensity factors which characterizes a systems ability to properly mix the Air/Fuel mixture and the combustion efficiency. Some possible improvement on the rotary geometry is suggested.
\end{abstract}

KEY WORDS: Internal combustion engines; Rotary valve; Engineering design; CAD; CFD

\section{INTRODUCTION}

Reciprocating spring loaded poppet valve systems, as found in most today's conventional automotive engines, depend on extremely stiff springs in order to ensure contact with camshaft lobe profile to avoid valve float, especially at high engine speed [1]. Although this can be performed with great accuracy, it also comes with the cost of creating significant amount of friction and vibration which will add to the total parasitic loses of the engine [2].

The most apparent solution to decrease these pumping losses, and hence, increase the overall engine output, would seemingly be to replace the reciprocating motion of the poppet valve system with a rotational porting system. The primary design advantage of a rotary system would be the absence of reciprocating components, and thus, the elimination of springs. Therefore, it shall create far less noise (vibrations) in the system, hence be a smoother running engine. Such porting system also has the advantage to be easily adapted to current engine configurations since its thermal cycle is theoretically identical to a poppet valve system.

${ }^{\dagger}$ Corresponding author. email: hoing@encs.concordia.ca

\subsection{Non-conventional rotary porting system}

Rotary valve porting systems have been around since the early 1900's [3-6] (see Fig. 1). Many patented engine designs using a horizontal-type rotary valve port system were commercialized in Britain on a very small production run in the early nineteen twenties by the Cross Manufacturing Company [4] and were mostly dedicated to motorcycle applications. However, one main flaw plagued this design concept until this day. The high pressure caused by the combustion process in the cylinder caused early designs of the shaft to cease due to high friction and bending moments. And, if trying to remedy this problem using some sort of counteracting coupling, or by simply allowing for more clearance interaction between the shaft and bearings, lubricating oil would spill into the combustion chamber and would quickly deteriorate the spark plug, not to mention exhaust large amounts of black smoke.

An axial rotary valve port system was proposed through a patented design by L.A. Vallillee in 1911 [5] as shown in Fig. 2. The rotating valve element in this case is positioned axially in the cylinder direction. In this case, the axial rotor spins about the cylinder axis and through an axially position slot in the rotor, inlets 
the air/fuel mixture passing through the cylinder, and exhausts the combustion mixture radially through a sleeve type porting system. As with the horizontal rotary valve, the combustion pressures tended to seize and warp the rotor, and many initial designs were quickly discredited. Later, a similar design was made by a British inventor named Aspin [6,7] (see Fig. 3). His first experimental engine was built in 1933 and variations of it were run in many motorcycle racing events. However his designs were plagued with excessive heating problems, due to friction, which warped the rotors. Later models, coated with leadberyllium, showed some improved characteristics, but were shortcoming as the coating would rapidly wear off.

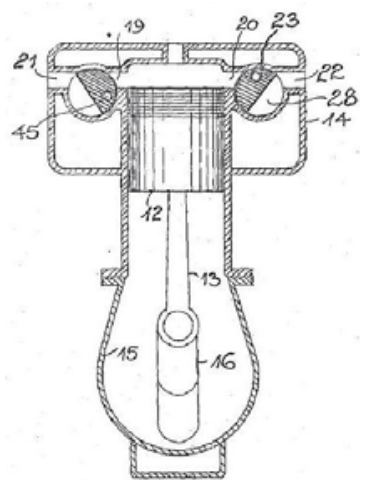

(a)

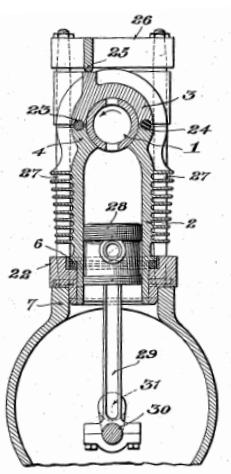

(b)
Fig. 1 a) Ritter's early patented concept of rotary valve system [3]; and b) Cross's rotary valve system [4]. (Figures from US patents \#1,135,719 and \# 2,169,631).

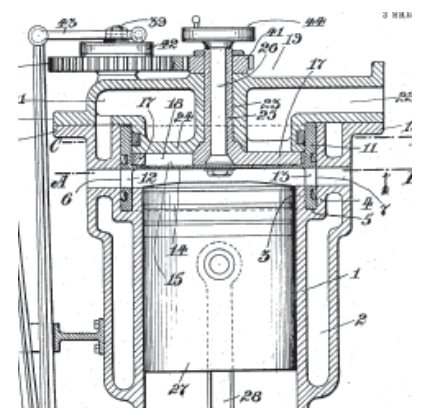

Fig. 2 Vallillee's axial rotary port system [5]. (Figure from US patent \#983,328).

\subsection{Old Concepts, New Technologies}

Close to a century has past since the first rotary port valve design, yet materials, technologies and processes evolve, and past concepts, such as the rotary valve system which were plagued with failures due to excessive wear and sealing problems, can be revised utilizing today's technologies in order to resolve the problems occurred in the past.

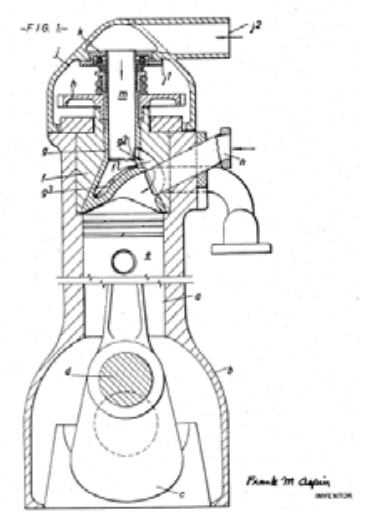

Fig. 3 Aspin's axial rotary valve design [6]. (Figure from US patent \#2,926,640).

One such example is a noteworthy manufacturer located in New Jersey, Coates International ltd [8-11], who holds several patents which were initially derived on early rotary valve designs. However, instead of using cylindrical shafts, spherical lobes with discrete passageways are used in order to insure fluid passage to and out of the cylinders. Another example is the collaboration between Mercedes-Ilmor and Bishop technology who have designed and fabricated a "Crosstype" rotary port valve system for their Formula V10 engine [12] (Fig. 4). Due to advancements in machinery technology, bore tolerances are calculated as such that the inherent mechanical and thermal distortions of the valves never interfere with the cylinder bore lining. The close tolerance between the shaft and the bore also prevents leakage between the exhaust and intake port. Unfortunately, the success of their venture never saw the day as Formula One regulation body, the FIA (Federation International de l'Automobile), had announced in 2004 the ban of such technology, thus eliminating the publicity window of Formula One as a marketing tool for any possible entry in the production world.
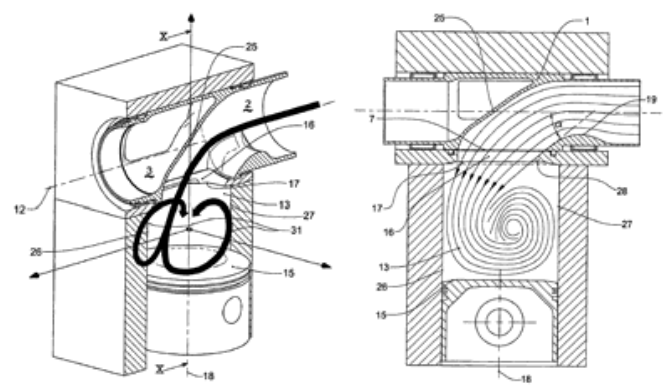

Fig. 4 Bishop rotary porting system [12]. (Figures from US patent \#7,584,741).

Reflecting on what has been discussed thus far, it is important to isolate some of the major problems and advantages associated with rotary porting concepts, and 
if possible look at various solutions from one design and incorporated them in another which should make for a considerable improved design. The Cross/Bishop type valve allows for continuous feed or exhaust via lateral positioned ports which remain open through the entire revolution of the valve. In contrast, the majority of Ritter/Coates type rotary valve concepts have lateral positioned ports which only have a short interval at which the passageways are fully open and gasses passing through these discrete passages form high turbulences at higher rpm caused by the leading and exiting sharp edges through the rotor [13]. This turbulence in turn will significantly lower the volumetric flow rate of the gasses passing through the passageway. Hence, a higher volumetric flow rate can be expected having the passageways axially positioned through the rotary valve, such as the Cross/Bishop designs. However, a non-Cross/Dual valve type design yet requires separate shafts to control intake and exhaust flow. The advantage of such design minimizes surface area per shaft exposed to the combustion chamber; hence thermal distortion is reduced, and allows for optimal positioning of a spark plug and/or fuel injector, located above and centered in the cylinder. Since smaller diameter ports are required, the compactness of the design will have as consequence of lowering the engines Center of Gravity (COG), an advantageous characteristic usually sought after in motorsport. Another advantage of the lather is the possibility to impose valve overlap in the porting system [1].

Table 1 lists the Pros and Cons of existing designs. By combining the advantages of all designs, it shall be expected that the resulting system should create a more effective porting system.

\begin{tabular}{|c|c|c|}
\hline & Pros & Cons \\
\hline $\begin{array}{l}\text { Single rotary valve } \\
\text { design } \\
\text { ( Cross/Bishop) }\end{array}$ & $\begin{array}{ll} & \begin{array}{l}\text { Continuous port feed } \\
\text { (higher volumetric }\end{array} \\
\text { efficiency) } \\
\text { - Simpler design } \\
\text { (less components } \\
\text { required) }\end{array}$ & $\begin{array}{ll} & \text { Large surface areas } \\
\text { exposed to combustion } \\
\text { (thermal/pressure } \\
\text { distortion) } \\
\text { - } \\
\text { No valve overlap } \\
\text { - Spark plug/injector not } \\
\text { at optimum position }\end{array}$ \\
\hline $\begin{array}{l}\text { Dual rotary valve } \\
\text { Design } \\
\text { (Ritter/Coates) }\end{array}$ & $\begin{array}{l}\text { - Lower surface exposure } \\
\text { to combustion pressures } \\
\text { \& temperatures } \\
\text { - Valve overlap possible } \\
\text { - Compact design (lower } \\
\text { COG) } \\
\text { Optimum spark } \\
\text { plug/injector position } \\
\end{array}$ & $\begin{array}{l}\text { Design requires } \\
\text { extra transmission drive } \\
\text { Existing patents have } \\
\text { discreet port feed (lower } \\
\text { volumetric flow } \\
\text { efficiency) }\end{array}$ \\
\hline $\begin{array}{l}\text { Axial type rotary } \\
\text { valves } \\
\text { (Vallillee/ Aspin) }\end{array}$ & - Continuous port feed & $\begin{array}{ll}\text { - Large surface areas } \\
\text { exposed } \\
\text { to combustion } \\
\text { (thermal/pressure } \\
\text { distortion) } \\
\text { - } & \text { No valve overlap } \\
\text { - } & \text { Spark plug/injector not } \\
\text { at optimum position } \\
\text { - Mechanism more } \\
\text { complex than other 2 } \\
\text { designs }\end{array}$ \\
\hline
\end{tabular}

Table 1 Pros and Cons comparison between existing rotary valve designs

\subsection{Objective of this study}

Isolating the Pros stated in Table 1, a simple hybrid design is proposed, shown in Fig. 5, as an initial concept which will incorporate a dual valve porting system laterally positioned (perpendicular to Crankshaft rotation), with axially positioned inner ducting ports which will allow continuous port feed, hence high volumetric efficiency expected, and have valve overlap capabilities whilst minimizing high pressure and thermal distortions due to lower exposed valve surface area in the cylinder.

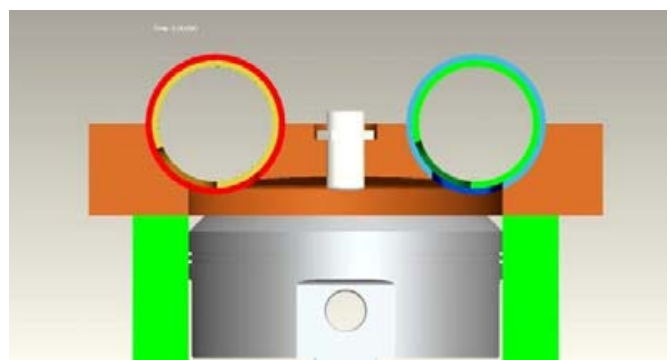

Fig. 5 Preliminary rotary valve hybrid design

The focus of this paper will be twofold: First to conceptualize a new design that is realistic (feasible), Second to demonstrate the potential advantage this system would have over a comparable sized engine. The comparison will be evaluated on two general aspects: Mechanical - assuming comparable conditions (material properties, friction coefficients, belt tensions, etc), evaluate mechanical advantage and give an indication on mechanical performance differences between both studied systems. Fluid dynamics - assuming comparable conditions (port size, piston diameter, displacement and velocity), compare systems volumetric efficiencies and give an indication on how well an engine can breathe (let air into the cylinders), and hence, increase total engine output.

In this study, the proposed hybrid design concept is compared to a similarly sized standard poppet porting system in term of mechanical peformance and volumetric efficiency using general Computer Aided Engineering (CAE) methods such as mechanical analysis using Computer Aided Design and Computational Fluid Dynamics (CFD). It is worth noting that although most modern engines are equipped with 4-poppet valves per cylinder for better valve timing control, a 2-poppet valve system is used in this study as a baseline of comparison with equivalent size/number of ports and the analysis results should be sufficient to suggest and demonstrate the potentials and simplicity of the rotary valves as an alternative valve system. The goal is to get a relative, quantitative comparison between both designs and demonstrate which of the two would be potentially the more efficient solution. With 
the latest accomplished, considerations will be taken on what other parameters can be studied in order to increase the rotary porting system designs efficiency.

For the purpose of this comparison, the proposed processes will be limited to virtual validation since no physical parts will be manufactured, thus no physical data collected. All CAD modeling and mechanical simulations of the virtual 3D models are done using Pro/Engineer Wildfire IV [14]. This CAD system is parametric which has the advantage of quickly modifying models at the change of a dimension or parameter. All Fluid Dynamics simulations are carried using the commercial CFDesign v10 software by Blue Ridge Numerics [15].

\section{PROPOSED ROTARY DESIGN CONCEPT}

\subsection{Engine design specification}

Since we are designing a concept from scratch, a Top/Down design methodology is used during the design process [16], which is characterized by linking the major dimensions of every part to a skeleton model. This allows for changes to be quickly propagated throughout the entire assembly in a single regeneration. Details of each design steps are omitted in this paper but can be found and explained in [17].

Table 2 lists the designed engine specifications that will be studied. The compression ratio is chosen to investigate if the design can withstand high combustion pressure under the upper operating limit of gasoline engines (Modern gasoline engines have generally 9-11:1 compression ratio). It would be natural to extend this design to diesel engine operation in the future work once the concept is proven and validated.

\begin{tabular}{|l|l|}
\hline Porting type & Dual shaft ports, $\phi_{\text {outer }}=30 \mathrm{~mm} ; \phi_{\text {inner }}=20 \mathrm{~mm}$ \\
\hline Piston Diameter & $86 \mathrm{~mm}$ \\
\hline Displacement & $120 \mathrm{~mm}$ \\
\hline Compression ratio & $12.5: 1$ \\
\hline Valve positioning & $\begin{array}{l}\text { Intake/Exhaust ports on same side, laterally } \\
\text { positioned in order to accommodate multi- } \\
\text { cylinder design (hence torque transmission } \\
\text { required) }\end{array}$ \\
\hline Materials used & All components assumed as Steel \\
\hline Spatial requirements & Include oil and water jacket passages \\
\hline
\end{tabular}

Table 2 Design specifications

Since the purpose of this study is specifically to compare efficiencies between standard and rotary valve engines, the auxiliary systems, such as lubrication and cooling systems, are vastly simplified and are present only for spatial considerations. In order to make a fair comparison to a standard poppet valve engine, the rotary valves are positioned perpendicular to the crankshaft such that a multi-cylinder rotary valve engine could easily be adapted. This imposition will entail the addition of multiple miter gears to change power transmission direction to the rotary valves and will consequently add frictional losses and weight to the assembly.

The final engine design is shown in Figs. 6 and 7, its exploded view and cross-sectional view in Figs. 8 and 9. Covers, oil sump and engine block are set with transparency in order to better visualize the assembly.
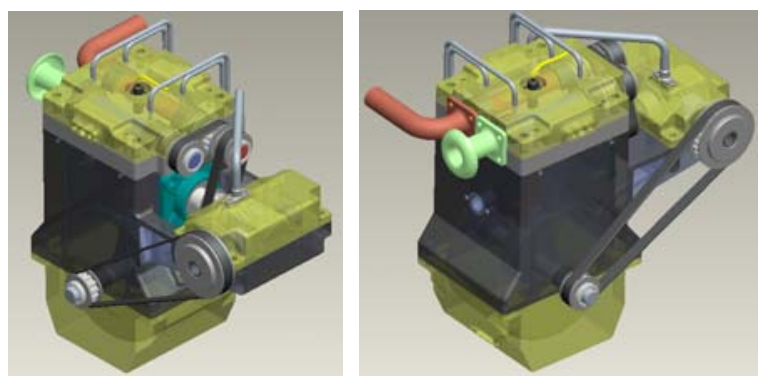

Fig. 6 CAD design, isometric views

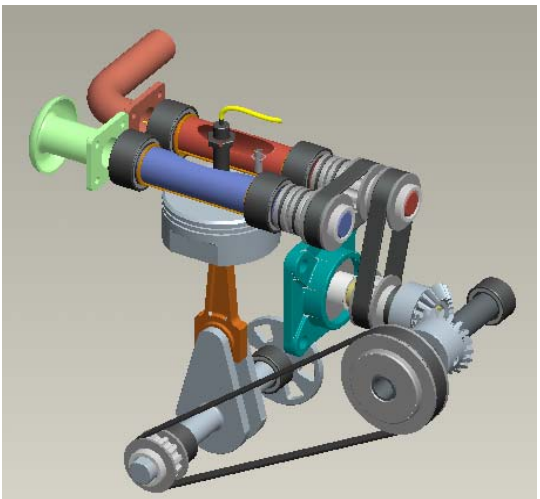

Fig. 7 Preliminary design, covers, sump and block hidden

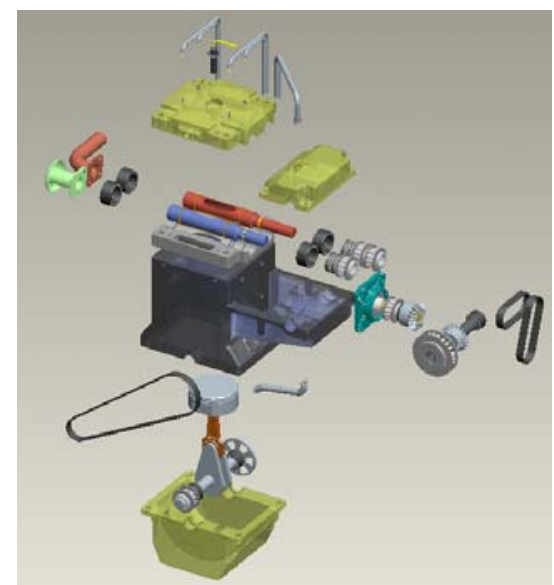

Fig. 8 Preliminary design, exploded view

To better understand the mechanism and assembly method, a closer look at the principal components and sub-assemblies are given presented with various section 
views. The first component which should be studied is the rotary valve itself. Noting that Fig. 10 represents a preliminary version of the rotary valve, it can be seen that several steps and grooves are necessary on the outer surface in order to accommodate bearings, seals and snap rings.

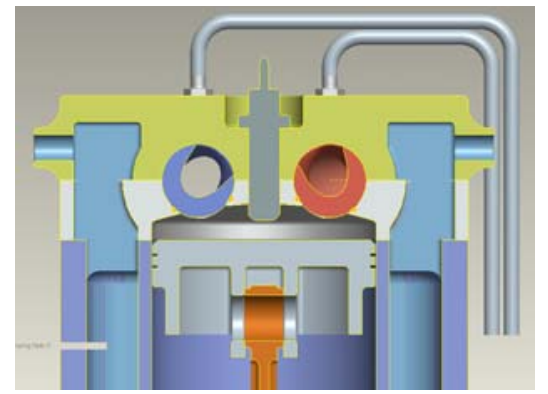

Fig. 9 Longitudinal cross-sectional view

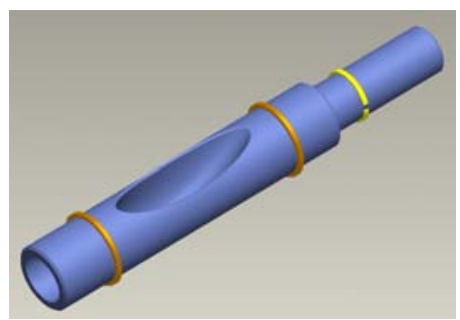

Fig. 10 Rotary valve drawing

From the section view presented in Fig. 11, the inner duct can be seen which allows fluid passage to/from the cylinder head. The progressive change in cross sectional area from inlet (circular cross section) to outlet (oval shaped) is controlled via intermediate sections strategically positioned along the centerline of the flow path. This preliminarily ensures that no flow detachments will occur and that the flow will be less turbulent inside the valve passageways and ports.
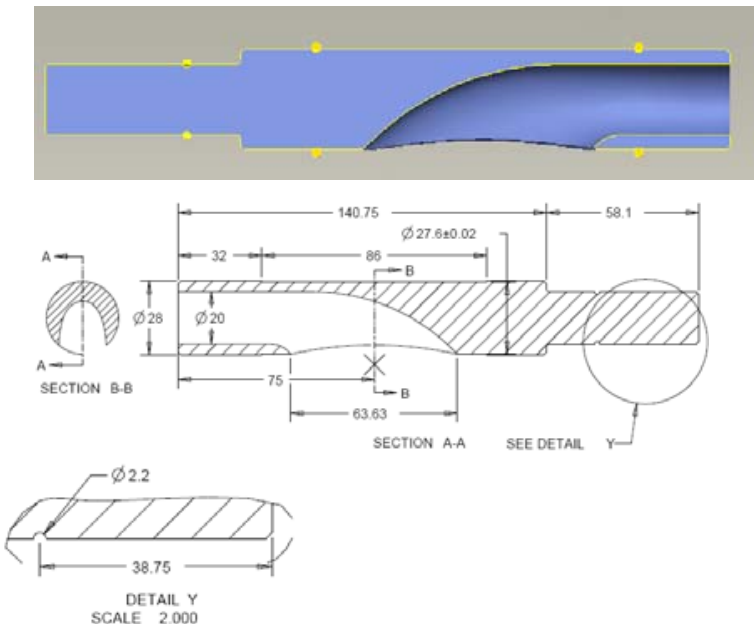

Fig. 11 Schematic of rotary valve with dimension (section view)
As for a standard poppet valve engine, the head subassembly is self-contained and can be assembled prior to be mounted to the rest of the engine. As can be seen in Fig. 12, the simplicity of the head assembly is one important advantage of this design. The compact design has a two fold advantage, the first is the ease to manufacture the parts (see Fig. 13) which compose the head assembly, and the second is to lower the center of gravity (COG) of the engine, especially critical in automotive racing applications. The entire bearing and seal package can be accommodated in the head assembly.

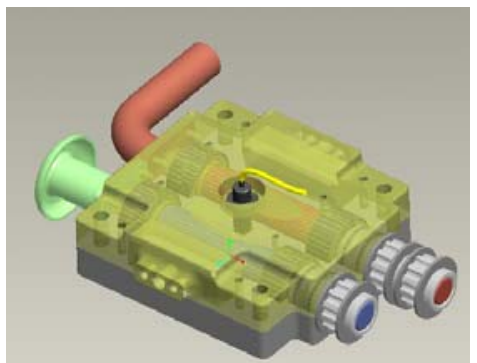

Fig. 12 Rotary valve sub-assembly

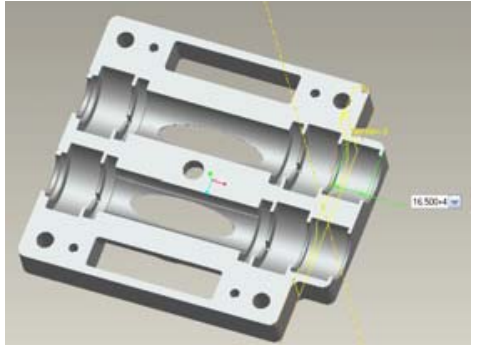

Fig. 13 Simplicity of engine head component

From Fig. 12, we can observe that the air intake (green mushroom shaped part) and exhaust are axially positioned with respect to the intake and exhaust valves. It can also be seen that three gears are present. The two inner gears are interconnected via a small belt and have a relative angle offset from one another. The outer gear located on the exhaust valve will connect to the transmission drive and will receive the power from the crankshaft. Two roller bearings, thrust bearings and face seals are present per rotary valve and are used to ensure low friction and sealing during high angular velocities. From the cross-sectional view in Fig. 9, it can be observed that two linear seals are mounted radially across the rotary valves in order to minimize leaks and should be of a hard, self lubricating material such as graphite, which has the added plus of sustaining high temperatures and pressures.

Clearances in the head should be sufficient to accommodate the bending loads caused by the combustion pressures in the chamber. According to [18], it is stated that typical values of cylinder peak 
combustion pressures are between 2-5 $\mathrm{MPa}$ for petrol engine. Since our design was configured for high-end gasoline engine operation with 12.5:1 compression ratio, an average peak pressure of $5 \mathrm{MPa}$ is chosen. To evaluate the distortions caused by such a pressure load, a Finite Element Analysis (FEA) is performed in order to observe the rotary valves distortion at loaded conditions. Pro/Mechanica [14] is used in order to conduct the FEA structural analysis. A mesh is created using the automatic meshing parameters and a static analysis run. From the results (Fig. 14) it can be seen that the shaft shall deflect a maximum of $0.0155 \mathrm{~mm}$. Therefore, these minimum clearances will have to be incorporated into the design of the head assembly.

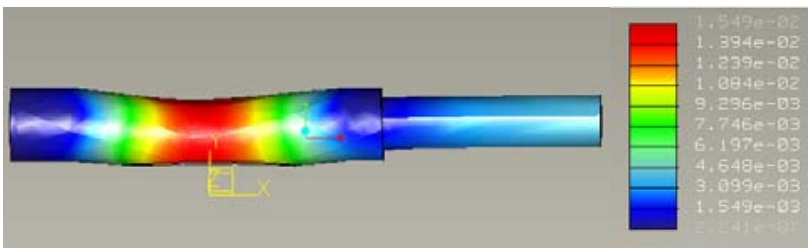

Fig. 14 Fringe plot at loaded conditions. Unit in [mm]

Another important component in the engine head is the sealing. Sealing methodology has always been a major problem with the rotary valve concept. Therefore, various seal technologies are studied and an optimum design is chosen for this proposed engine. Sealing technology is quite extensive and proper selection is crucial for the lifetime expectancy of the moving components. The main functions of a seal are to retain lubricants, exclude contaminants, separate fluids or gases and withstand differences in pressure. An improperly sealed mechanism will have their lubrication system contaminated and lead to eventual failure of dynamic components such as bearings and shafts.

Many factors influence the choice of an appropriate seal at operating conditions, such as the type of lubrication used (greases or oils), relative sliding velocities at the sealing surface, mounting position of seal in assembly (vertical or horizontal), possible missalignments or deviation from coaxiality of the shaft, chemical, thermal or electro-mechanical unbalancing of material properties [19]. Space and cost constraints are usually also of prior importance. SKF, being a world leader in both bearing and sealing technology, have extensive documentation for proper selection of sealing components on rotating shafts [19].

Generally, the criteria which are of primary importance are operating speeds and maximum operating temperatures. Since the rotary valves will be revolving at one half crankshaft speed, and that most automotive road applications red line at $6000 \mathrm{rpm}$, we can assume that the maximum operating conditions will be near $3000 \mathrm{rpm}$. Seals and bearings are usually rated in linear (circumferential) velocity rather than angular speed; therefore with shaft radius of $0.03 \mathrm{~m}$, a proper conversion gives a linear velocity of $9.425 \mathrm{~m} / \mathrm{s}$.

At this linear speed, the lowest velocity rating of the SKF seals is still valid, rated at $14 \mathrm{~m} / \mathrm{s}$, however, for long life cycles, some safety factor should be considered and thus, the higher rated velocity seals should be selected. Also, since most engines run well above $100^{\circ} \mathrm{C}$, the higher temperature rating seals should be preferred, which contain a fluoro-rubber compound. As secondary selection criteria the property of the seal to handle oil on one side, in this case the lubrication system on the bearings and bushings of the rotary valve, is taken into consideration.

Based on the above criteria, from the selection guide table [19] it is possible to narrow the initial selection to the following seal family groups:

1. CRW1-CRWH1: Waveseal single lip, Steel shell (double in the case of CRWH1).

2. CRWA1-CRWHA1: Waveseal double lip, steel shell (double in the case of CRWHA1).

3. CRW5-CRWA5: Waveseal single lip(double lip for CRWA5), steel shell.

These seals are of the radial face type category and are characterized by the presence of an outer steel sheet metal shell which is statically fit into a bore of an assembly, and has an inner elastomeric ring which is clamped to the rotating shaft via a garter spring. The lip of the rotating ring is the contact area which creates the seal between the outer casing and the rotating shaft. SKF has performed substantial research which has led to an innovation in sealing technology, namely the Waveseal lip. The Waveseal lip design represents one of the most important developments in radial shaft seals during the past 25 years [19]. The waveseal lip has the front and rear faces of the lip hydrodynamically formed to a sinusoidal shape. The resulting shape decreases surface pressure in the sealing lip and in consequence produces $20 \%$ less friction which results in substantially lower operating temperatures and increased seal life.

Since this technology did not exist at the time of the first patents on rotary valve technology, it is hoped to achieve considerable improvements on the life time of our design integrating this new design. SKF does offer recommendation and engineering services which could better suit our application, however since the goal of this research is to analyze and compare the mechanical and fluid advantages of the studied system over the standard poppet IC engine, further resources should be dedicated to this aspect when the requirements of a physical model is brought ahead, and all detailed mechanical aspects will have to be looked at thoroughly. For a preliminary design purpose, the single lip CRW1 can be selected for illustration. 
Further design consideration should be taken to lubricate the sealing lip in order to efficiently seal over long periods of time. This will reduce friction at the contact area and reduce the amount of wear on the lip, not to mention the operating temperature of the elastomeric material at the seal face. Our current design contains lubrication passages which feed the bearings and bushing areas of the rotary valve. Additional passages should be included in order to wet the lip area of the seals. As discussed earlier, the lubrication system is positioned such that it can feed both the bearings and seals (Fig. 15) simultaneously. The rotating valve ensures the motion action of the oil which is then drained through an opposing hole located under the rotary valves.

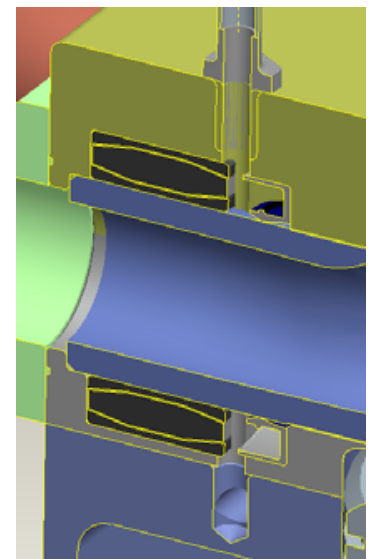

Fig. 15 Assembly of CRW1 radial seal in preliminary design

The engine block is slightly more complex than a standard IC engine due to the requirements of the transmission case which is longitudinally positioned on the component (Fig. 16). However this complexity can be reduced by separating the transmission case region as a separate part and mechanically linking both components. The location of the transmission case becomes apparent when considering a multi-cylinder design. From Fig. 17, it can be observed that a single transmission shaft could be used in order to run all rotary valves of the engine.

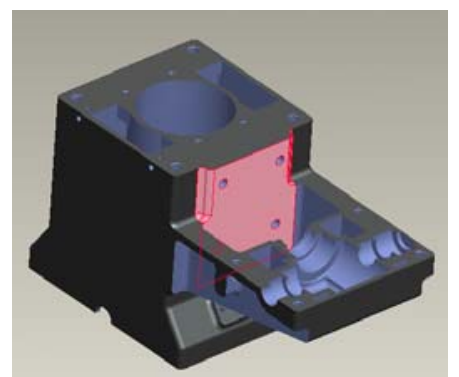

Fig. 16 Schematic of the engine block

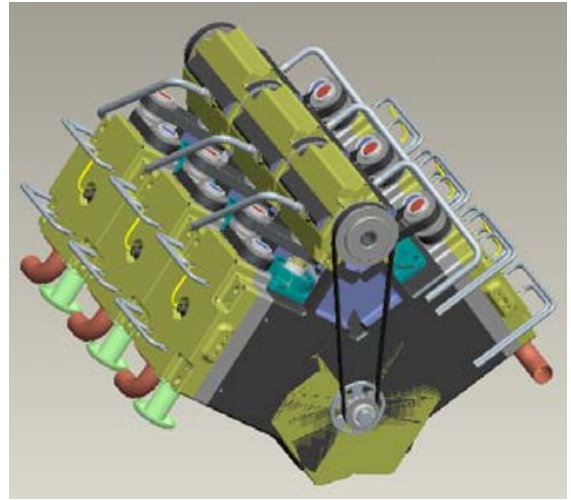

Fig.17 Six-cylinder V configuration

The transmission drive is performed via gears, sprockets and belts which interconnect the crankshaft, transmission shaft and rotary valves (Fig. 18). The relative velocity between the crankshaft and the rotary valves is $2: 1$ (valves rotate one half the speed of crankshaft), this is imposed using sprockets that have a pitch differential of 2:1. A mounted bearing is used on which a miter gear, a roller bearing and a sprocket gear are assembled to and will be capable of absorbing the reaction loading transmitted by the transmission shaft. The section presented in Fig. 18 also shows the addition of the second bearing, positioned as far out as possible on the shaft, will eliminate any shaft bending.

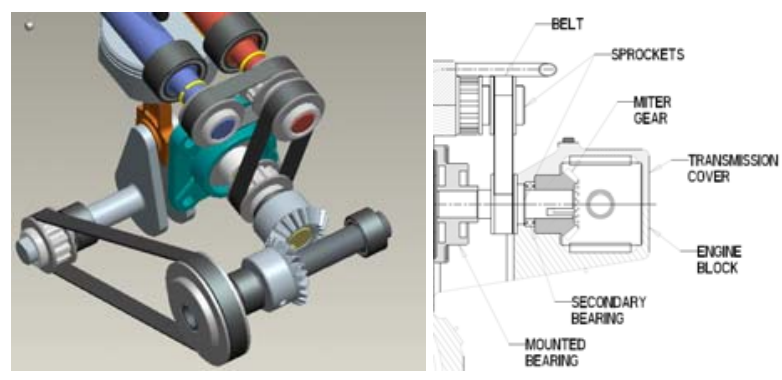

Fig. 18 Valve transmission drive and the position of secondary bearing

Finally, as stated previously, cooling and lubrication systems, although simplistic, have been integrated into the design for spatial study purposes only. Fig. 19 highlights the lubrication circuit, and the cooling circuit.

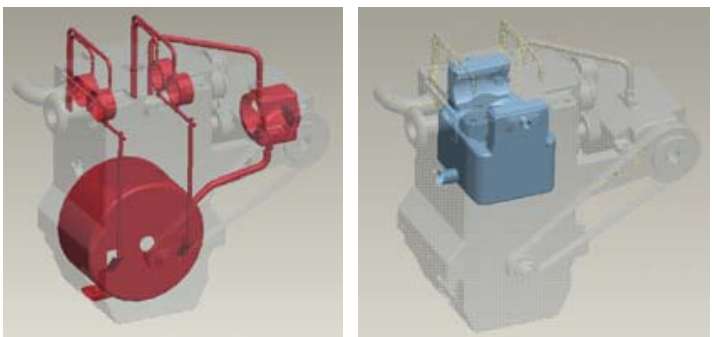

Fig. 19 Lubrication and cooling circuit 


\subsection{Standard poppet valve engine equivalent}

In order to model a standard poppet valve engine which has comparable characteristics to the rotary valve design proposed, the engine block and engine displacement must remain the same in both designs, and the intake cross sectional area must be equivalent.

Since the inner diameter of the rotary valve was set at $20 \mathrm{~mm}$ (see Fig. 11). Therefore the intake crosssectional area for the standard poppet valve engine should be of equivalent size and for simplicity, is modeled as a swept circular cut of $20 \mathrm{~mm}$ diameter (see Fig. 20).

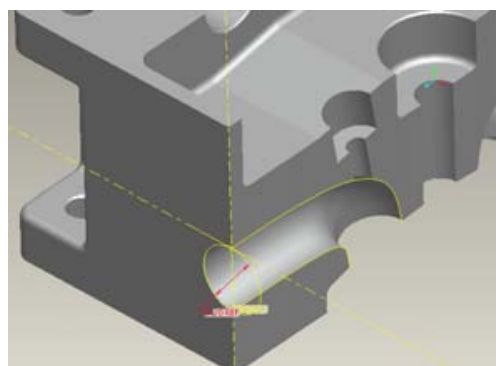

Fig. 20 Intake circular swept cutout of $20 \mathrm{~mm}$ diameter in engine block

A head sub-assembly is created, where along with the head itself, valves, seats, spacers, springs, camshafts, bearings and seals are included (Fig. 21). A copy of the entire lower engine assembly (block, sump, crankshaft, piston, connecting rod, etc.) is performed and the block is simplified in order to accommodate the standard head assembly (see Fig. 22).

In this manner, the inner geometrical components remain exactly the same for both the rotary and standard engines, which is a requirement for a fair performance comparison between both designs. The section views in Fig. 23 demonstrate the inner geometrical similarities of both designs.

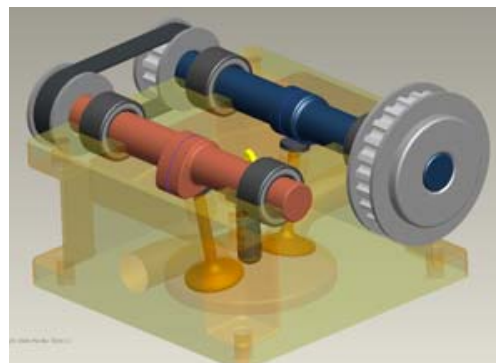

Fig. 21 Standard head sub-assembly section view

With the geometry of both designs finalized, analyses of the mechanical and fluid characteristics of both systems can next be performed and discussed in following sections.
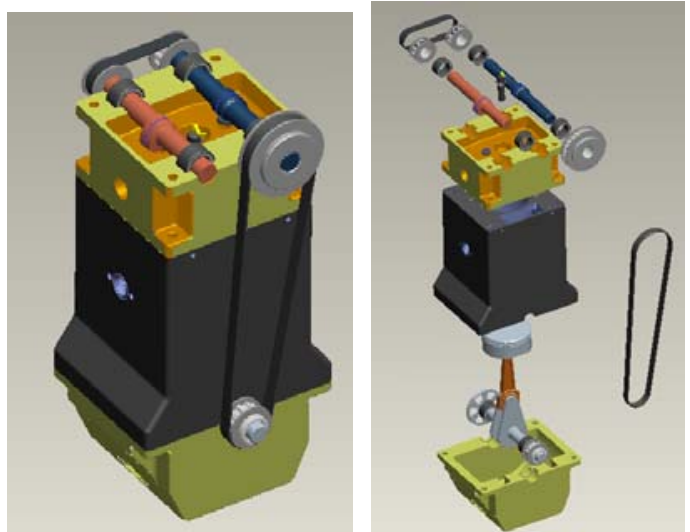

Fig. 22 (a) Standard engine assembled view; (b) Standard engine exploded view
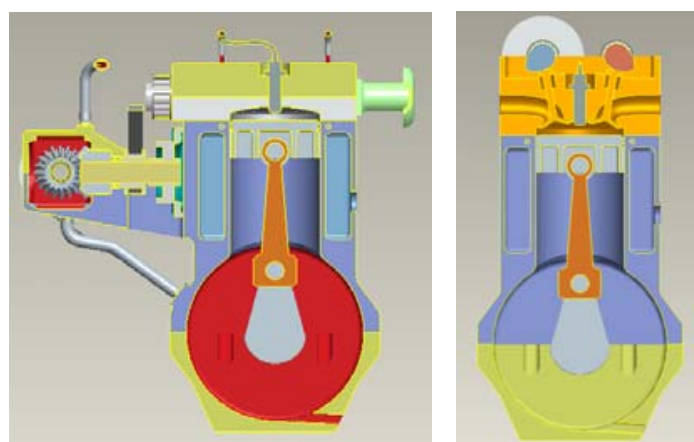

Fig. 23 Section view comparison of designs (a) Rotary valve design; (b) Standard design

\section{MECHANICAL ANALYSIS}

The Mechanism Dynamics Extension (MDO) of Pro/Engineer [14] is used in order to obtain a global torque input required in order to run both porting designs at engine speeds of 2000 and $3000 \mathrm{rpm}$. This module takes into account the inertial and spring forces present in the system, thus proper assignment of material density is crucial. In order to maintain reciprocity between engine designs, all dynamic parts are assigned steel properties.

In order to account for frictional losses, static and dynamic friction coefficients are applied at the joint locations. Once again, in order to maintain similarities between designs, static and dynamic coefficients at all joints are set to 0.6. Lastly, belt tensions are neglected since they are of comparable magnitude in both designs. Common kinematic constraints in Pro/Engineer used in both our analysis are CAMS, PINS, GEARS and SPRINGS [14]. 


\subsection{Mechanical analysis of rotary valve design}

Since we are only interested in comparing required torques to run the porting systems, the aforementioned will be isolated from the rest of the engine, hence removing from the analysis the torque required to revolve the crankshaft/piston assembly, and thus isolating parasitic loads caused by the porting system (Fig. 24).

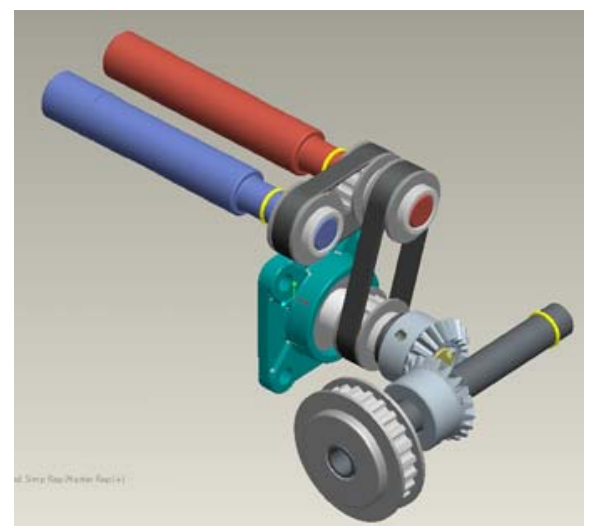

Fig. 24 Isolation of porting system for dynamic analysis

The dynamic analysis is setup using mechanism constraints and servo motors applied on the transmission shaft with angular velocities of $6000 \% \mathrm{sec}$ $(1000 \mathrm{rpm})$ and $9000^{\circ} / \mathrm{sec}(1500 \mathrm{rpm})$, one half the required engine velocities (2000-3000 rpm). Joint definitions are then altered to include friction coefficients. Dynamic analyses are then run with friction and gravity effects included. With the analysis completed, a Net Load measure is created in order to record the peak load in the system. For example, Fig. 25 depicts torque requirement at an engine speed of 3000 rpm.

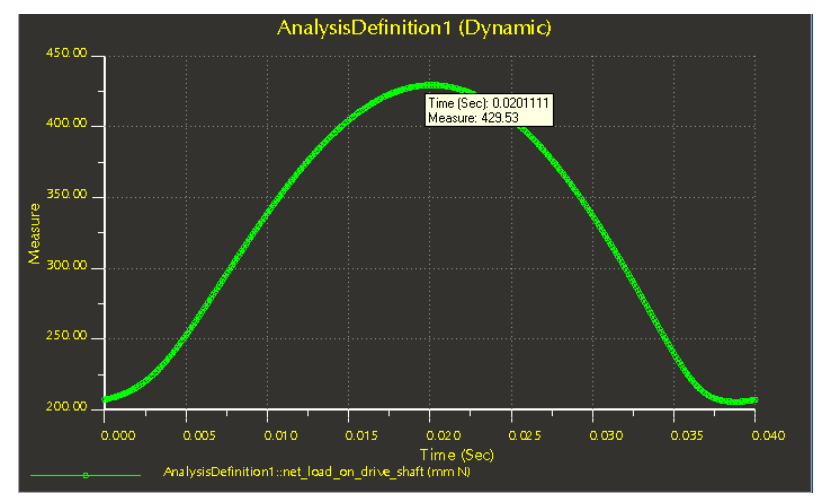

Fig. 25 Net load on rotary porting system at $3000 \mathrm{rpm}$

From the simulations, it is found that peak torque requirements at 2000 and $3000 \mathrm{rpm}$ engine speeds are $325.4 \mathrm{~N}-\mathrm{mm}$ and $429.5 \mathrm{~N}-\mathrm{mm}$, respectively.

\subsection{Mechanical analysis of standard design}

Before we can calculate the total loading requirements on the standard engine design, it is first necessary to determine the minimum necessary spring rate in order to eliminate valve float. We will use the relation:

$$
F=k \cdot x=m \cdot a
$$

where $F$ is the force acting on valve $(\mathrm{N}), k$ the spring constant $(\mathrm{N} / \mathrm{m}), x$ the spring deformation w.r.t. free length $(\mathrm{m}), \mathrm{m}$ the poppet valve mass $(\mathrm{kg})$ and a the poppet valve acceleration $\left(\mathrm{kg} \cdot \mathrm{m} / \mathrm{s}^{2}\right)$. From the 3-D geomertry, we have $m=0.0319 \mathrm{~kg}$, free spring length = $0.017 \mathrm{~m}$ (Note: The free spring length is determined with zero preloading at valve in shut position of zero lift) and $x=0.008 \mathrm{~m}$.

In order to obtain the maximum acceleration, the CAM constraint linking the valve spacer and camshaft are set to zero liftoff. In this matter, the valve will never detach from the surface of the camshaft (hence inherently eliminating valve float) and a measure is created to record the maximum acceleration of the valves.

From the simulation results, the maximum acceleration the poppet valve will experience with current cam profile geometry is $440 \mathrm{~m} / \mathrm{s}^{2}$ at $3000 \mathrm{rpm}$. Hence substituting this value in the spring constant equation above, the resulting minimal (since no preloading is imposed) spring stiffness $k=1754.5 \mathrm{~kg} / \mathrm{s}^{2}$ $(1.7545 \mathrm{~N} / \mathrm{mm})$.

At this point, the cam constraints are reset to "lift off enabled" and springs constraints created between the engine head and poppet valves with the above determined parameters (Fig. 26). A measure which keeps track of valve float is created and is used to make sure our estimated minimal spring stiffness is sufficient to keep the poppet valve spacer mated to the profiled surface of the camshaft.

With the above completed, the dynamic analysis is run for two complete crankshaft revolutions (one full engine cycle).

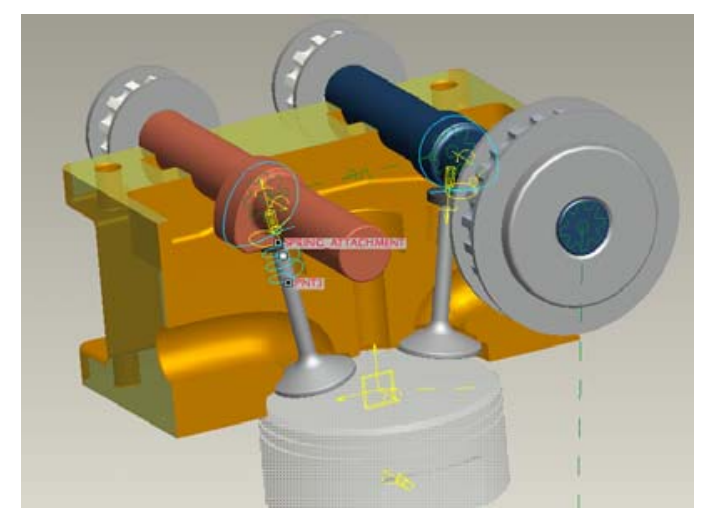

Fig. 26 Spring constraints creation 
From the valve float measure, we can see that a substantial valve float occurs $(0.5 \mathrm{~mm})$ at current spring stiffness. The underestimation of the spring stiffness is due to the neglected friction forces, since the above calculations were for static equilibrium and do not account for dynamic forces.

Therefore, stiffening of the spring is required. In order to eliminate all valve float, the spring stiffness must be increased to $9.0 \mathrm{~N} / \mathrm{mm}$ (Fig. 27) in order to reduce valve float from $0.5 \mathrm{~mm}$ to $0.07 \mathrm{~mm}$.
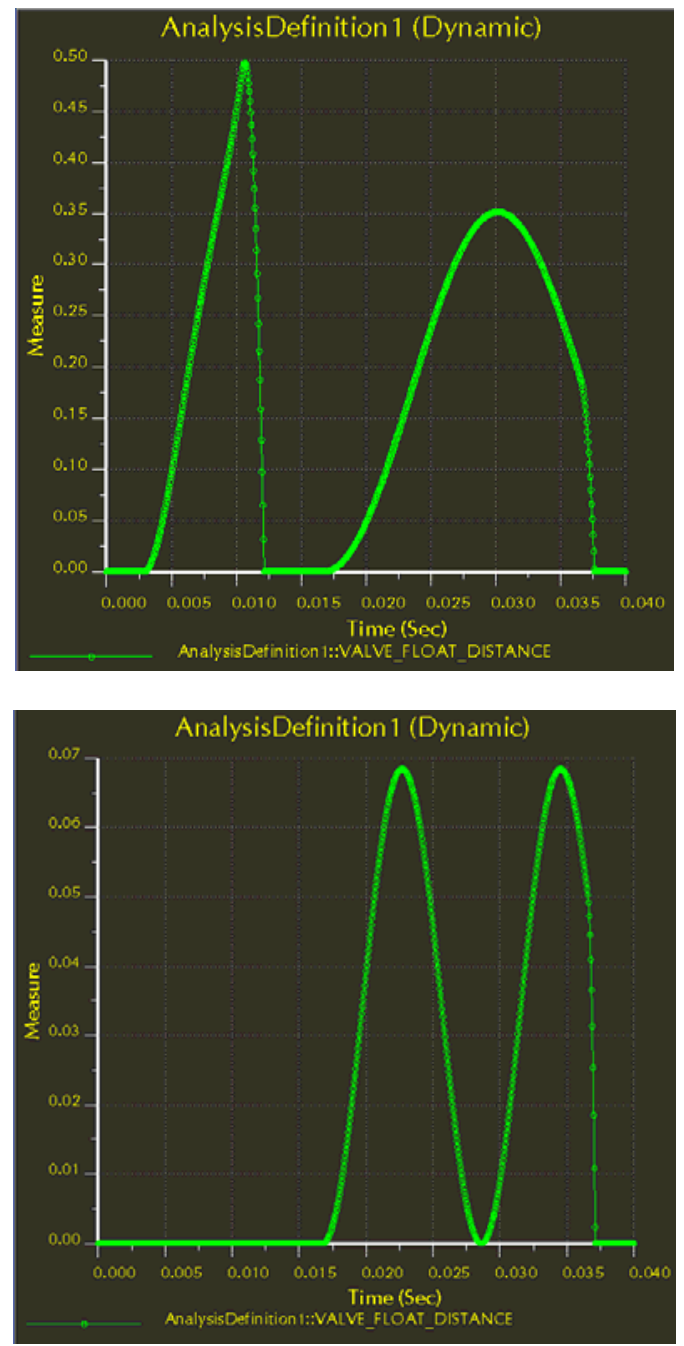

Fig. 27 a) Valve float measure before spring stiffening b) Valve float measure after spring stiffening

With the spring stiffness determined, we can now turn our attention to the required torque input to actuate the porting system. As was done for the rotary valve design, the porting system is isolated (Fig. 28) and a measure is created which will record the net load at the intake camshaft, hence simulating the required torque input to run the engines porting system at studied engine speeds (crank speeds). For example, Fig. 29 illustrates the net load on poppet valve porting design at $3000 \mathrm{rpm}$.

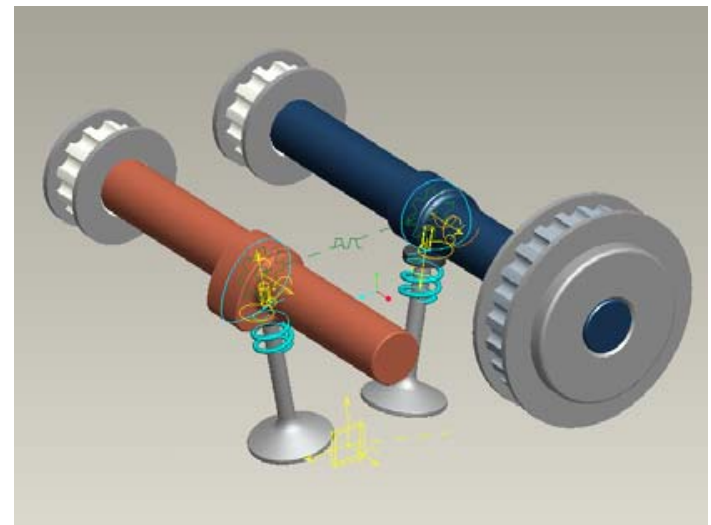

Fig. 28 Isolation of porting system for dynamic analysis

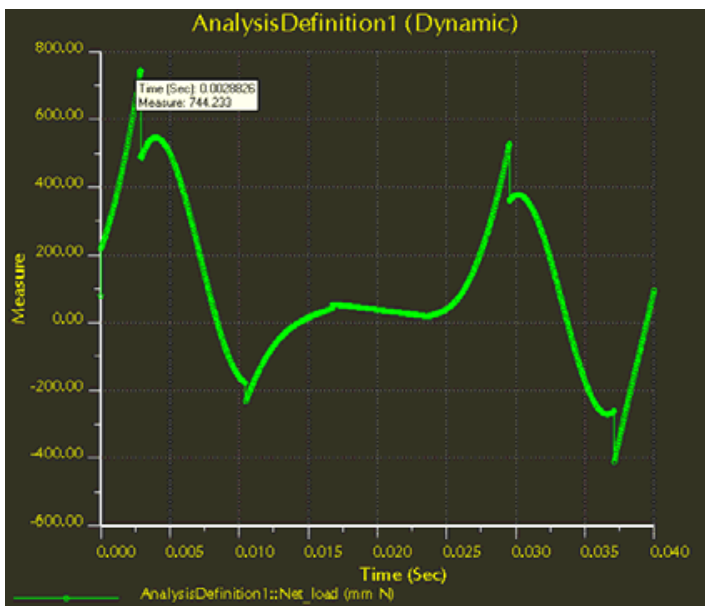

Fig. 29 Net load on poppet valve porting design at 3000 rpm

From the measured results, the peak torque at engine speeds of $2000 \mathrm{rpm}$ and $3000 \mathrm{rpm}$ are $699.4 \mathrm{~N}-\mathrm{mm}$ and $744.2 \mathrm{~N}-\mathrm{mm}$, respectively.

\section{COMPUTATIONAL FLUID DYNAMIC ANALYSIS}

In this section, Computational Fluid Dynamics CFD code is used, namely CFDesign v10 by Blue Ridge Numerics, in order to evaluate and compare the total volumetric flow rate aspirated into the cylinders in both designs at two different engine speeds (2000 and 3000 $\mathrm{rpm})$. Streamline characteristics are also compared in order to observe the turbulence characteristics of the flows.

The CFD solver is a Finite Element Solver which solves unsteady, compressible, 3-D viscous flows using non-linear Navier-Stokes (momentum) equations 
coupled with conservation of Mass, Energy and/or State Equations [20]. The CFD code also uses turbulence models in order to approximate turbulence velocity fields which would otherwise be too complex to solve with the above stated equations. For inner turbulent flows with high Reynolds number $k-\varepsilon$ (k-epsilon) model should be used in order to avoid diverging solution and to obtain good results for reciprocating engine flow applications [21-25].

The first step will be to create simplified representations of the geometry in Pro/Engineer. For the rotary valve system, all solid components are removed except for the rotary valves, piston and cylinder. Capping geometry is required in order for CFDesign to create the void (inner fluid) volume geometry. To do this, a simplified engine head and block are created. The CFD model for this configuration is shown in Fig. 30.

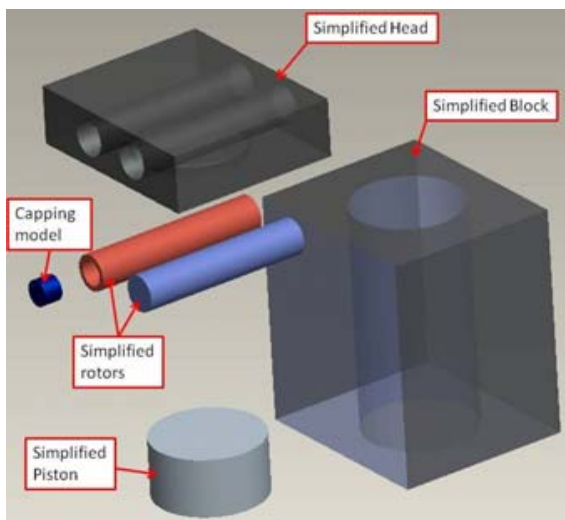

Fig. 30 CFD simplified model for the rotary valve system

The same activity is performed for the standard engine design; however in this case, the poppet valves are included into the analysis. The CFD model for the standard design is shown in Fig. 31.

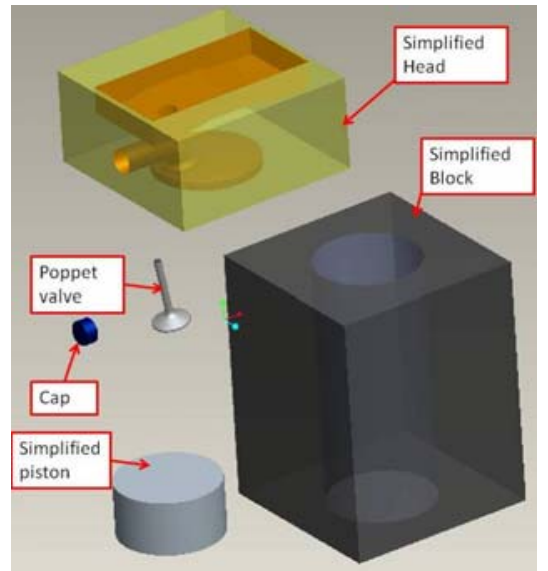

Fig. 31 CFD simplified model for the standard system
At this point, since CFDesign is linked to Pro/Engineer sessions, the geometries are brought into CFDesign and pre-processing of the model is performed As stated at the beginning of this section, once solutions have reached convergence, streamlines, volumetric flow rates and turbulence intensity factors will be recorded and compared.

Streamline characteristics will be determined by visual interpretation while volumetric flow rates will be recorded using the cutting plane bulk functionality at inlet ports for both designs. Turbulent intensity factors for both designs will also be recorded. Turbulence intensity factor is a characteristic magnitude of turbulence. Since high turbulence promotes fuel/air mixing, the higher this factor, the greater the mixing in the combustion chamber and the quicker the combustion process will occur [26]. Therefore, turbulence intensity factors inside the cylinder for both designs will also be visually compared.

\subsection{CFD analysis of rotary valve design}

Once the flow has reach repeated trend characteristics, i.e., flow momentum has stabilized, convergence can be assumed. Cutting planes are used in order to extract data on specific planes. A cutting plane perpendicular to the inlet is used to visually verify the flow characteristics, while a cutting plane normal to the inlet duct will allow us to extract volumetric flow rates at that particular section. Fig. 32 show the volumetric flow rate vs. time at 2000 and 3000 rpm crankshaft velocity.

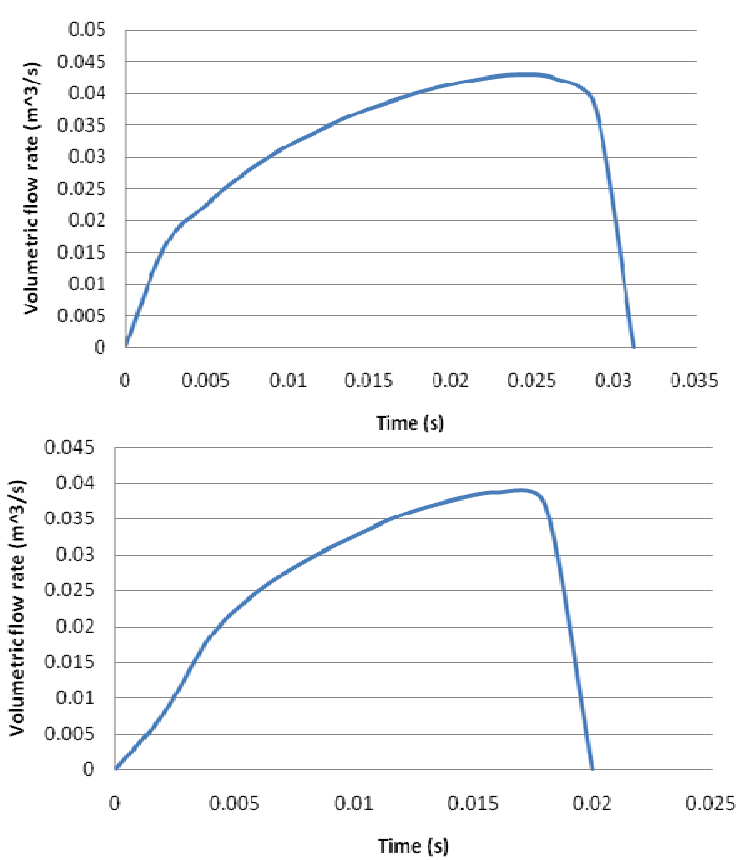

Fig. 32 Volumetric flow rate $\left(\mathrm{m}^{3} / \mathrm{s}\right)$ vs. time (s) for rotary valve intake cycle at $2000 \mathrm{rpm}$ (top) and 3000 rpm (bottom). 
To illustrate the turbulent nature of the flow field, Fig. 33 shows the vector plots at various rotary valve positions at $3000 \mathrm{rpm}$. Using traces, as shown in Fig. 34, the flow inside the chamber becomes highly turbulent as the piston reaches TDC at $3000 \mathrm{rpm}$.

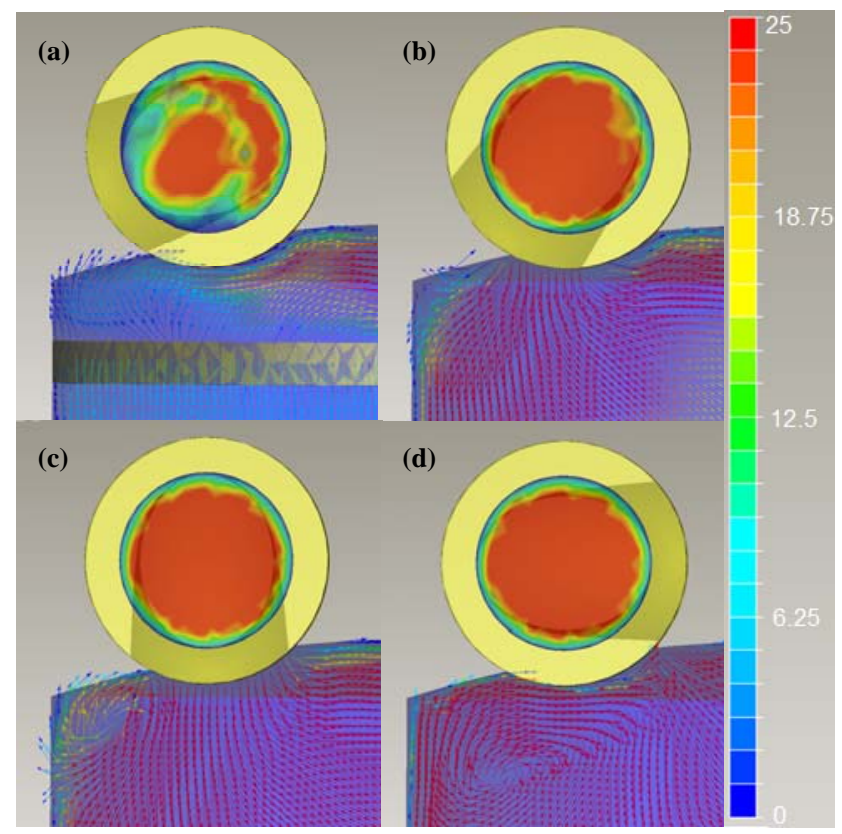

Fig. 33 a) Vector plot $[\mathrm{m} / \mathrm{s}]$ at $t=0 \mathrm{~s}$ shows rotary valve in closed position (i.e. no flow into cylinder); b) Vector plot as valve starts opening, laminar behavior as flow enters chamber; c) As valve reaches maximum aperture, flow entering cylinder is still laminar; d) Once inlet valve has completely closed, chamber vortices grow.

Fig. 35 demonstrates the turbulence intensity factor distribution [21] for the rotary valve system at TDC for a $3000 \mathrm{rpm}$ crank speed, where maximum turbulence and mixing should occur. An IsoSurface of magnitude 0.5 is also used in order to display the cloud volume where the intensity factor is equal or lower to 0.5 . Turbulence intensity factor is a characteristic magnitude of turbulence. Since high turbulence promotes fuel/air mixing, the higher this factor, the greater the mixing in the combustion chamber and the quicker the combustion process will occur. Furthermore, in SI engine, the higher the turbulent intensity level usually leads to a faster flame speed and makes the engine's thermodynamic cycle more ideal and decreases the knock tendency [26]. Mathematically explained [21], it is a measure of the strength of the local turbulence in the fluid, defined by:

$$
\text { Turbulence intensity factor: } I=0.16 \mathrm{Re}^{-1 / 8}
$$

where Re is the local Reynolds number.

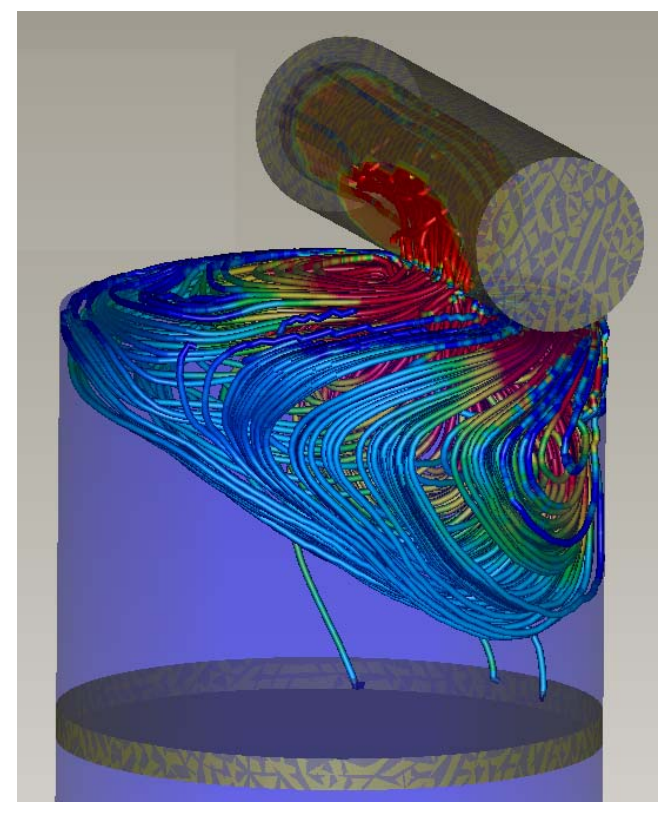

Fig 34 Trace plot showing the flow inside the cylinder near the inlet valve just prior to its closing

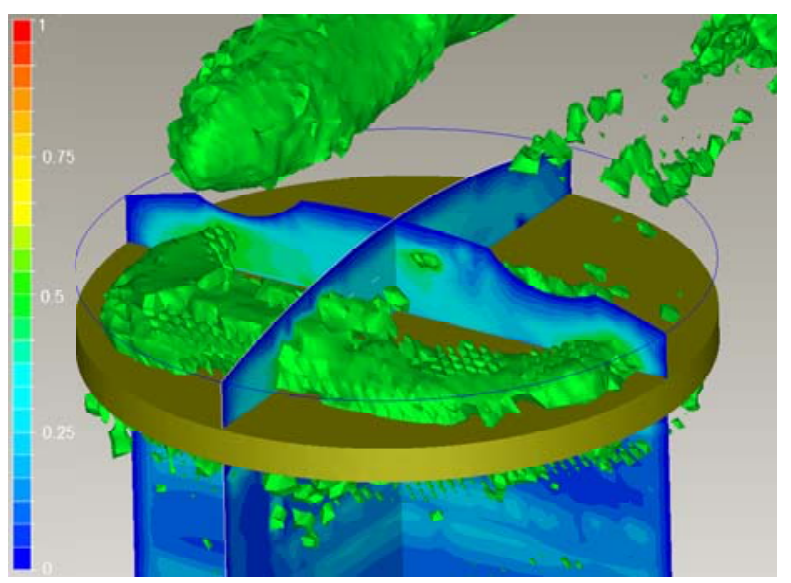

Fig 35 Turbulence intensity factor distribution for rotary valve system

\subsection{CFD analysis of standard design}

As was done for the rotary valve engine, from the cutting planes, we can once again extract visual information and volumetric flow rates over a complete cycle at the inlet (see Fig. 36). 

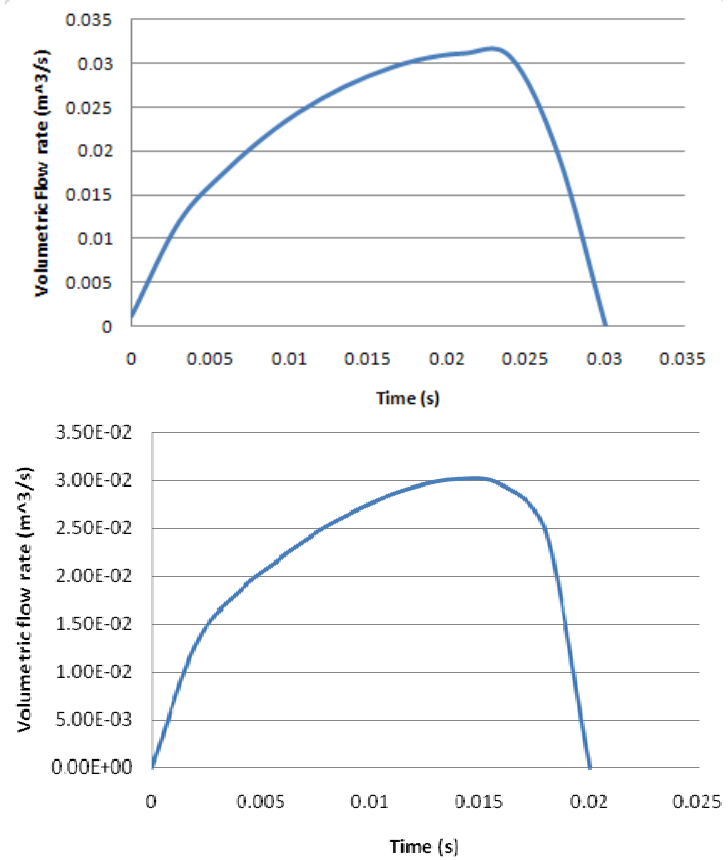

Fig. 36 Volumetric flow rate $\left(\mathrm{m}^{3} / \mathrm{s}\right)$ vs time (s) for poppet valve intake cycle at $2000 \mathrm{rpm}$ (top) and 3000 rpm (bottom) crankspeed

Fig. 37 shows vector plots at various valve positions at $3000 \mathrm{rpm}$ engine speeds. Equivalently, Fig. 38 shows the trace plots at maximum poppet valve opening for $3000 \mathrm{rpm}$ engine speed.

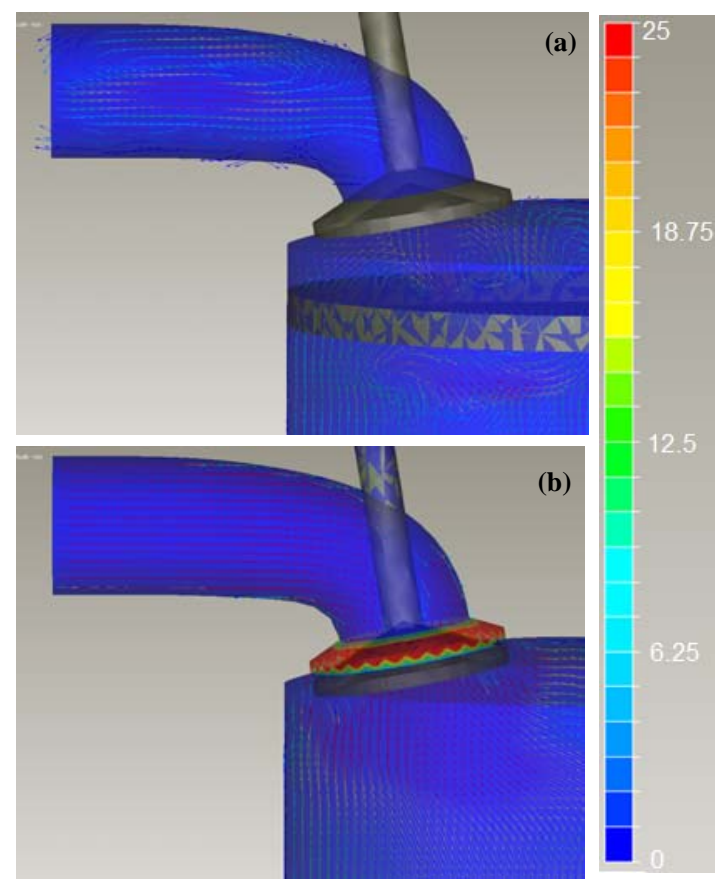

Fig. 37 (continued)

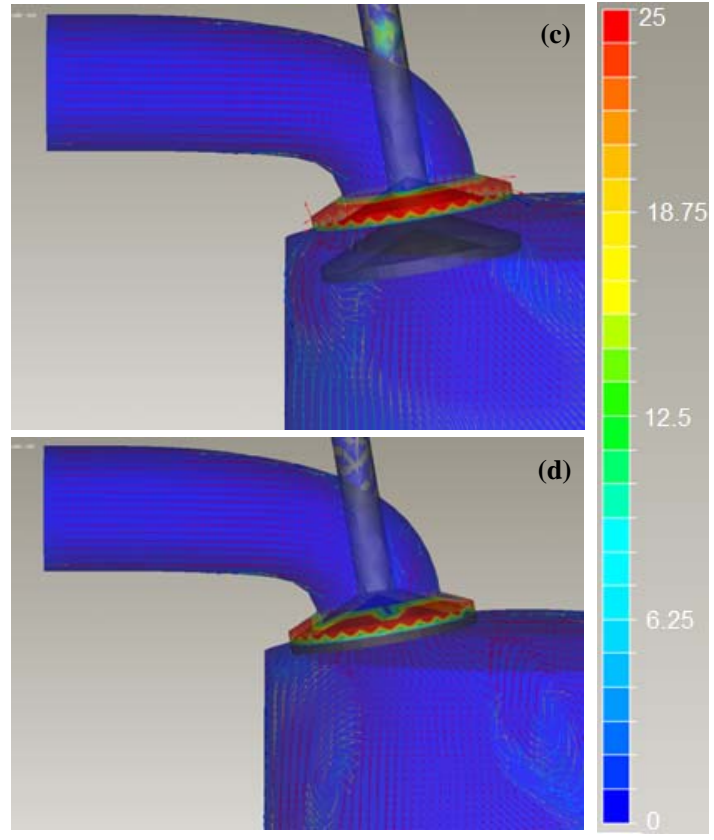

Fig. 37 a) Vector plot at $t=0 \mathrm{~s}$ shows recirculation in the inlet duct and weak vortices in the chamber; b) Vector plot as valve starts descending shows laminar behavior as flow enters chamber; c) As valve reaches maximum displacement, inner vortices start forming in the chamber; d) Once inlet valve has completely closed, chamber vortices continue to grow

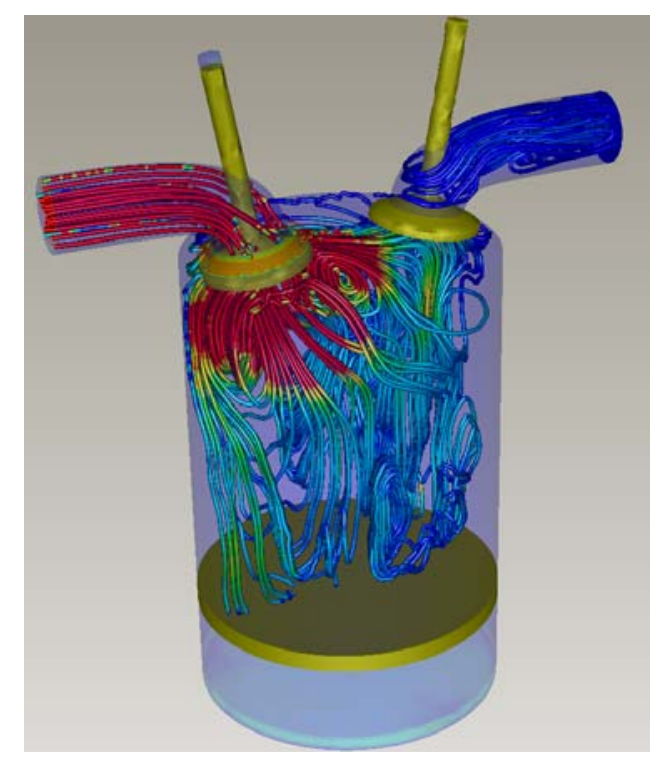

Fig. 38 Trace plot shown at inlet valve maximum displacement 


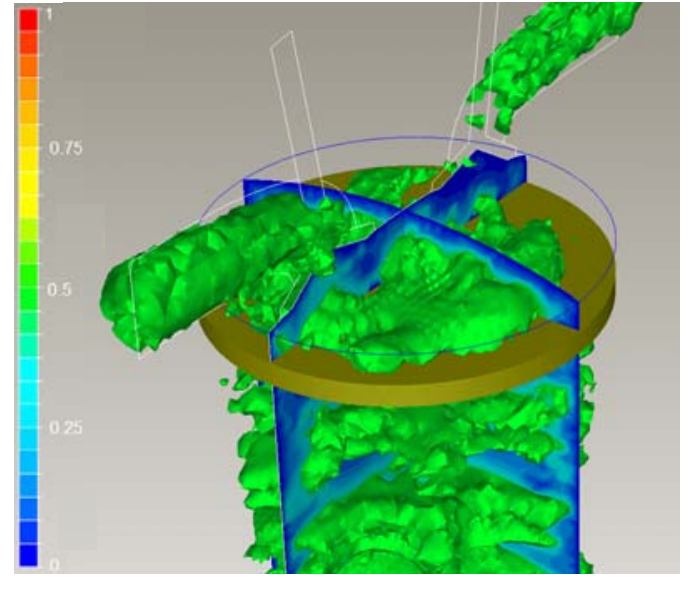

Fig. 39 Turbulence intensity factor distribution for poppet valve system

Observing Fig. 38, the flow within the chamber is also highly turbulent in the poppet valve system. The turbulence intensity factor distribution is shown in Fig. 39.

\section{RESULTS DISCUSSION}

\subsection{Mechanical analysis result}

As seen in section 3, the dynamic analysis allowed the measurement of peak torques of both porting systems, the results are tabulated in Table 3.

\begin{tabular}{|c|c|c|}
\hline $\begin{array}{l}\text { Porting } \\
\text { system }\end{array}$ & $\begin{array}{l}\text { Peak torques @ 2000 } \\
\text { rpm (N-mm) }\end{array}$ & $\begin{array}{l}\text { Peak torques @ 3000 } \\
\text { rpm (N-mm) }\end{array}$ \\
\hline Rotary & 325.4 & 429.5 \\
\hline Standard & 699.4 & 744.2 \\
\hline
\end{tabular}

Table 3. Peak torques recorded in porting systems

Comparing both systems, the standard porting system requires more than $50 \%$ torque at $2000 \mathrm{rpm}$, and greater than $40 \%$ at $3000 \mathrm{rpm}$. However, two points are critical: The greater the balancing of the crankshaft, the more important is the parasitic loses on the engine efficiency. The greater the number of cylinders and valves per cylinder, the greater the parasitic load, and thus, the higher importance of having an efficient porting system. Also to be noted is that mechanical analysis performed on the standard porting engine system was extremely conservative since spring stiffness were taken as minimal to eliminate valve float at $3000 \mathrm{rpm}$. This would be considered conservative since most engines can run well beyond $3000 \mathrm{rpm}$, thus requiring substantially stiffer springs. Therefore, it can then be stated with confidence that a rotary valve design would be a more efficient porting system when considering the mechanical efficiencies of both designs.

\subsection{CFD analysis result}

In section 4, the fluid dynamic analysis allowed the measurement of volumetric flow rates of both porting systems, the results are tabulated below.

\begin{tabular}{|c|c|c|}
\hline $\begin{array}{l}\text { Porting } \\
\text { system }\end{array}$ & $\begin{array}{l}\text { Peak v_flow @ 2000 } \\
\text { rpm }\left(\mathbf{m}^{\mathbf{3}} / \mathbf{s}\right)\end{array}$ & $\begin{array}{l}\text { Peak v_flow @ 3000 } \\
\text { rpm }\left(\mathbf{m}^{\mathbf{3}} / \mathbf{s}\right)\end{array}$ \\
\hline Rotary & 0.043 & 0.039 \\
\hline Standard & 0.03 & 0.03 \\
\hline
\end{tabular}

Table 4 Peak volumetric flows recorded in porting systems

When comparing results, it can be seen from Table 4 that the rotary valve porting system allows for greater amounts of air to enter the chamber. Comparing peak values, this works out to approximately $30.2 \%$ higher volumetric flow rate in the rotary valve design at 2000 rpm and $23.1 \%$ at $3000 \mathrm{rpm}$. Observing the flow rates of the standard porting design, it can be seen that there is very little increase in volume flow rate for increase engine velocity. Referring to Fig. 40, it can be seen that some areas with Mach numbers of 1 start occurring (red region), which leads to choked flow characteristics (i.e. no further increase of flow rate possible).

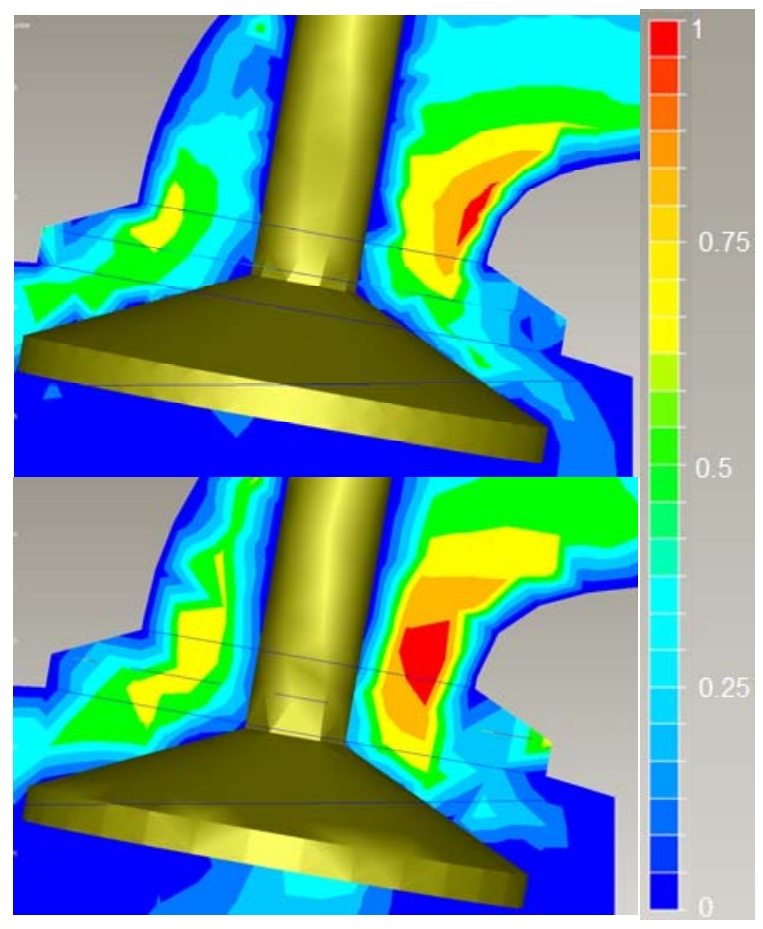

Fig. 40 Mach number fringe plot at $2000 \mathrm{rpm}$ (top) and at $3000 \mathrm{rpm}$ (bottom) standard porting system

Comparing the entire flow range at $3000 \mathrm{rpm}$, from Fig. 41 it can also be seen that the rotary porting system will breathe with a higher efficiency throughout the entire inlet cycle 


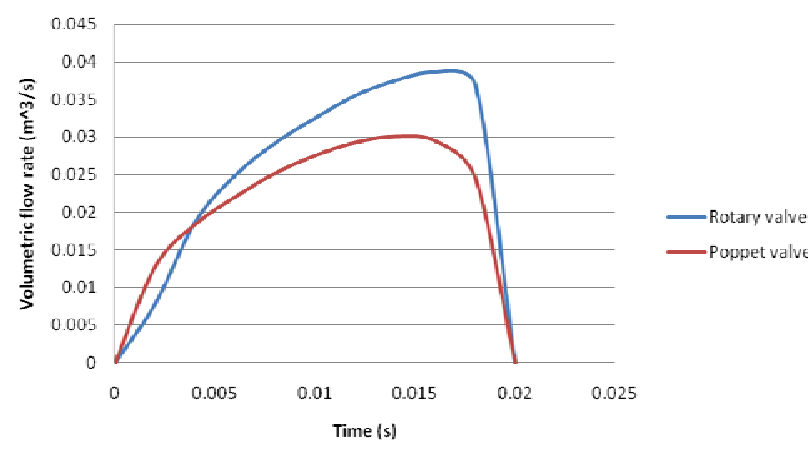

Fig. 41 Volumetric flow rate comparisons of both systems.

Observing the vector plots from previous section, this higher efficiency can be explained by the unobstructed flow path in the rotary valve design as compared to the poppet valve design as the piston reaches TBC.

In Figs. 35 and 39, the turbulence intensity factors at $3000 \mathrm{rpm}$ are compared visually in order to obtain a qualitative validation of which system will offer better fuel/air mixing capabilities. As can be seen, the poppet valve system has a slightly larger turbulent flow at TDC, this effect can be primarily attributed to the fact that the poppet valve acts as an obstruction to the incoming air as the piston moves to BDC, hence the air entering the chamber is already turbulent. The movement of the piston back to TDC simply increases the intensity of the already turbulent air. Although it may appear that slightly lower turbulent intensity is observed for the rotary valve system, it should not be considered as a demerit of the proposed design. it is worth noting that turbulence can be promoted through other design components inside the combustion cylinder such as the piston head cavity, pre-swirl inlet guide, cylinder head geometry, etc. In fact, from a fluid dynamic point-ofview, a lower turbulence level near the ports may provide a smoother flow passage with higher volumetric efficiency [13].

From these analysis results, it can therefore be concluded that the breathing characteristics of the rotary valve design has the potential to achieve the same level of efficiency of the conventional poppet valve design, however its mixing and combustion capabilities may be slightly less ideal.

\section{ROTARY VALVE ITERATION ANALYSIS}

In this section, iterations of the rotor are analyzed in order to evaluate trends which will optimize the performance characteristics of the rotary porting system. Two studies are conducted here. One is to evaluate the effects of rotor outlet cross section area, and thus changing the inner duct characteristics from converging nozzle, to constant cross section, and finally to diverging; the other is the performance comparison between the baseline geometry and a simplified geometry.

\subsection{Duct characteristics performance}

Noting that the baseline geometry at $2000 \mathrm{rpm}$ used thus far will be used as the diverging duct geometry, two additional models are created which will have their inner ducts modified in order to obtain the constant cross sections and converging area ducts. The geometries used and respective dimensioning for the performance comparisons are shown in the following Figs. 42-44:
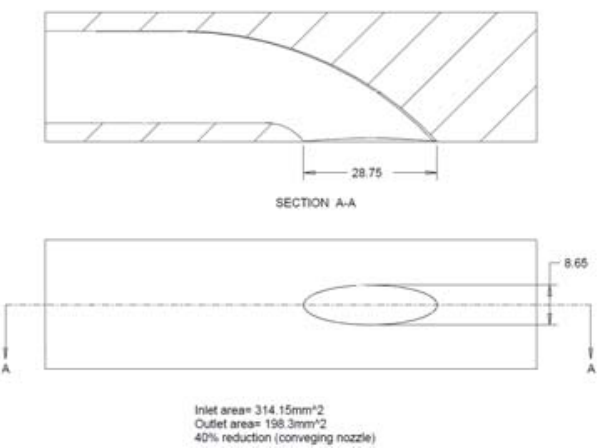

Fig. 42 Converging nozzle cross section duct
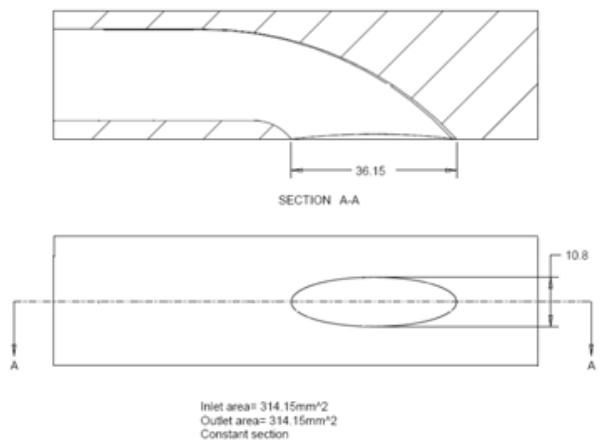

Fig. 43 Constant cross section duct
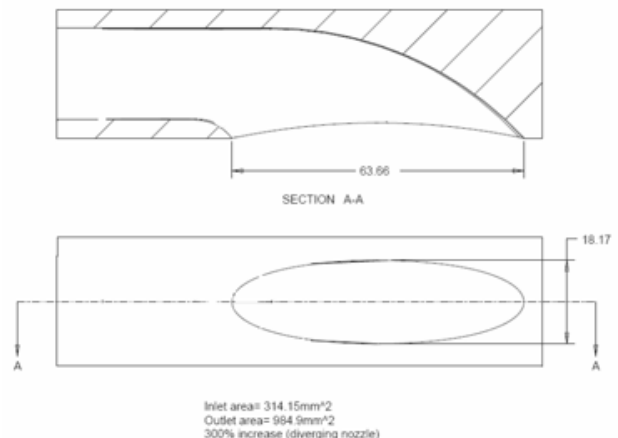

Fig. 44 Diverging nozzle cross section duct (baseline) 
Using the same methodology used in order to evaluate volumetric flow rates from the previous analysis, Fig. 45 graphically demonstrates the performance difference obtained by varying the inner duct geometry.

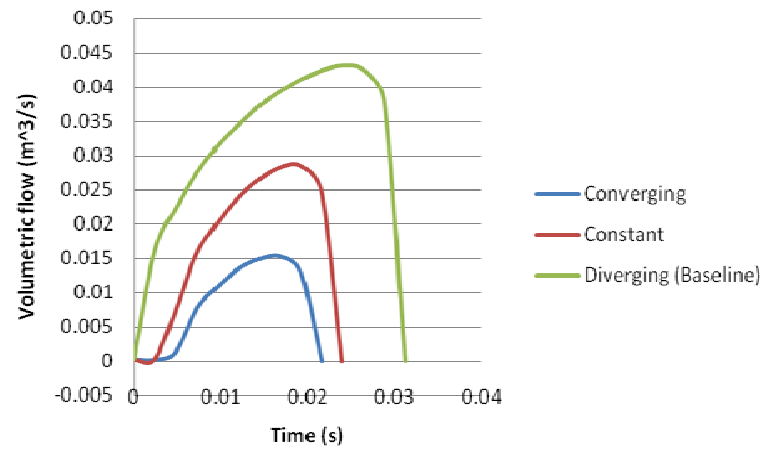

Fig. 45 Performance difference varying inner duct geometry

Clearly the baseline geometry (diverging duct) yields the best breathing characteristics (greater than 33\% more than the constant area duct) for the rotary valve porting system and should be used for any future studies.

\subsection{Simplified geometry comparison}

As briefly discussed in previous section, the manufacturing of the baseline geometry inner duct could be quite difficult and expensive to fabricate. Therefore, a simplified geometry performance characteristics will be compared to the baseline at 2000 rpm in order to evaluate the compromise to be accepted if manufacturing costs become a factor. The simplified geometry will have both the inlet and outlet sized to the exact dimensions of the baseline geometry, as shown in Fig. 46. The results are compiled over the intake stroke and shown in Fig. 47.
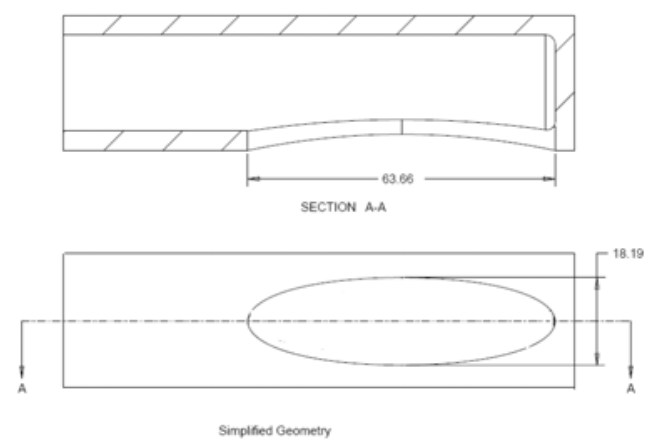

Fig. 46 Simplified machined rotor

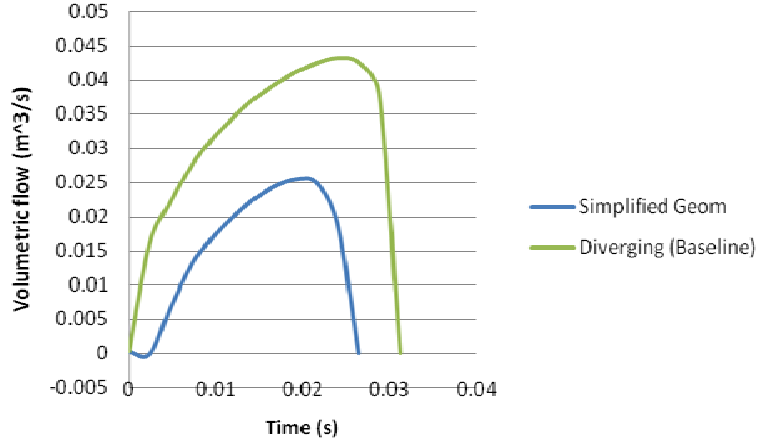

Fig. 47 Simplified geometry performance comparison to baseline

As expected, the volumetric flow rate is substantially lower for the simplified geometry configuration (approximately $41 \%$ lower). However, referring back to Table 4, the peak volumetric flow rate of the simplified geometry is only $15 \%$ lower than the standard poppet valve porting system. Considering the substantial mechanical advantage the rotary valve system will have on the total output, then the simplified geometry configuration should still be advantageous when looking at the global performance of both systems.

\section{CONCLUSION}

Through comparisons of existing designs, a hybrid rotary valve porting system was conceived. Researching latest sealing technologies, the suggested design was then modified in order to accommodate proper seals which, as stated earlier, should be well adapted to handle high velocity, low lubricated areas on the journal surfaces of the rotary valves.

It was then proven through simulations, mechanical and fluid, that a rotary porting system, while simpler with the absence of reciprocating components, does have considerable potential to achieve the same comparable efficiency of the poppet valve systems. It is proven in this study that a rotary valve design would be a more efficient porting system when considering the mechanical efficiencies of both designs. It eliminates the spring loaded mechanism and the reciprocating motion required for a poppet valve system. The rotary valve can also be designed to achieve the same level of volumetric efficiency of the conventional poppet valve design, however its mixing and combustion capabilities may be slightly less efficient, but yet can be improved through other design components. These advantages can be translated into greater specific output power or fuel economy and reduce parasitic losses. 


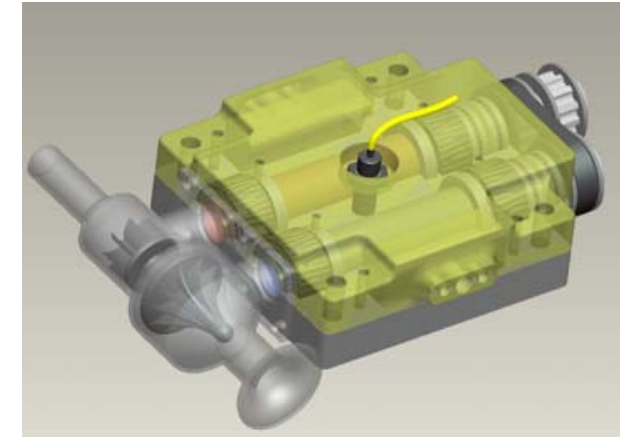

Fig. 48 Retrofit of turbo-compressor to rotary valve porting system

The concepts explored in this research should prove useful as a baseline for designing a more detailed rotary porting system and exploring further eminent solutions which can increase engine efficiency. For future works, some issues can be readily suggested. Having modeled basic geometry in both cases, efficiencies of the rotary valve porting system can still be well optimized. Just as can be done with the poppet valve system, rotary valve overlap can be controlled by simply changing the phase between shafts. Furthermore, if multi-physics CFD would have been accessible, the effects of having a smaller exhaust port shaft would have been another interesting characteristic to evaluate since, as is the case for standard poppet valve systems, the exhausted gasses have a much higher pressure and velocity than inlet gasses, and thus do not require to have equal sized porting as the inlet. Finally, as can be seen in Fig. 48, retrofitting a turbocharger or compressor to a rotary valve porting system would be a fairly simple and interesting concept to be studied further in order to increase overall system performances. However, extension of this concept to multi-cylinder engines as shown in Fig. 17 may be challenging and thus requires further design and development.

\section{REFERENCES}

[1] Heywood, J.B. (1988) Internal Combustion Engine Fundamentals. McGraw-Hill, Inc. New York.

[2] Ciulli, E. (1992) Review of internal combustion engine losses. Pt.1: specific studies on the motion of pistons, valves and bearings. J. Automobile Eng., 206: 223-236.

[3] Ritter, R. (1915) Valve Gear for Internal Combustion Engines. US patent \#1,135,719, April $13^{\text {th }}, 1915$. United States Patent Office.

[4] Cross, R.C. (1939) Rotary Valve Engine. US patent \#2,169,631 August 1939. United States Patent
Office. (see also: Cross manufacturing company limited. http://www.crossmanufacturing.com/)

[5] Lavallillee, L.A. (1911) Internal Combustion Engine. US patent \#983,328, Feb $7^{\text {th }}, 1911$. United States Patent Office.

[6] Aspin, F.M. (1960) Internal Combustion Engines. US patent \#2,926,640, Mar. ${ }^{\text {st }}, 1960$. United State Patent Office.

[7] JW's Aspin Essay, March 2009 http://www.isdm.co.uk/aspin/AspinEssay/essay.htm

[8] Coates, G.J. (1991) Spherical Rotary Assembly for an Internal Combustion Engine. US patent \#4,989,558, Feb. 5, 1991. United States Patent and Trademark Office.

[9] Coates, G.J. (1992) Spherical Rotary Valve. US patent \#5,109,814, May 5, 1992. United States Patent and Trademark Office.

[10] Coates rotary valve - http://www.coatesengine.com/, 1999.

[11] Coates, G.J. (2004) Rotary valve and valve seal assembly for engine with hemispherical combustion chambers. Sealing Technology, 10: 13.

[12] Wallis, T. (2007) The Bishop rotary valve, Bishop technology. Magazine Autotechnology, special 2007. see also: US patent \#7,584,741, Sept. 2009. United States Patent and Trademark Office.

[13] Pignone, G.A., Vercelli, U.R. (1995) Motori ad Alta Potenza Specifica, Vinodrome (Milan, Italy), Giorgio Nada publications 1995, p55, 168.

[14] Pro/Engineer Wildfire 4.0 - http://www.ptc.com/

[15] Technical Manual for CFDesign v10 by Blue Ridge Numerics - www.cfdesign.com/

[16] Buede, D.M. (1999) The Engineering Design of Systems: Models and Methods. John Wiley \& Sons.

[17] Palmisano, R. (2009) Design analysis and comparison between standard and rotary porting systems for IC engine. Masters thesis, Concordia University.

[18] Lumley, J.L. (1999) Engines, an Introduction. Cambridge University Press, 1999

[19] SKF, Principals of Sealing selection guide http://www.skf.com/ .

[20] Anderson J.D., Jr. (2007) Fundamentals of Aerodynamics. $4^{\text {th }}$ edition, New York (USA), McGraw Hill publications 2007, pp141,809,813.

[21] Technical Manual for CFDesign v10 by Blue Ridge Numerics - www.cfdesign.com/

[22] Pope, S.B. (2000) Turbulent Flows. Cambridge University Press.

[23] Auriemma, M., Corcione, F.E., Macchioni, R. and Valentino, G. (1995) Assessment of the k- $\varepsilon$ turbulence model in KIVA-II by in-cylinder LDV measurements. Society of Automotive Engineers, paper \# 952385.

[24] Ahmadi-Befrui, B. and Gosman, A.D. (2005) Assessment of variants of the k- $\varepsilon$ turbulence model 
for engine flow applications. Int. J. Numerical Methods in Fluids, 9: 1073-1086.

[25] El-tahry SH. And Haworth, D.C. (1992) Directions in turbulence modeling for in-cylinder flows in reciprocating engines. J. Prop. Power, 8: 1040-1048.

[26] Ferguson, C.R. and Kirkpatrick, A.T. (2001) Internal Combustion Engines- Applied Thermosciences. $2^{\text {nd }}$ edition, John Wiley \& Sons, Inc. 